\title{
Charlotte Stilwell: 'The prosthodontic spectrum is very wide now'
}

Interview by Ruth Doherty

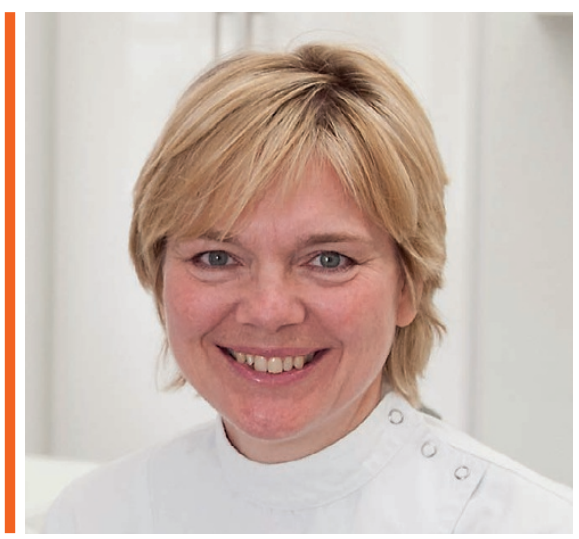

Charlotte Stilwell is a specialist in prosthodontics. She qualified from the Royal Dental College in Copenhagen in 1983 and moved to London to pursue her interest in removable prosthodontics. After five years of post-graduate training in the Prosthetic Department, Royal London Hospital Dental School she practised for nine years in general practice in West Wickham, Kent. She then moved to her current practice position as a referral specialist in Harley Street in London. Charlotte has an interest in conventional and implant prosthodontics and management of occlusion. She is also a lecturer at the Division of Gerodontology and Removable Prosthodontics, University of Geneva, and an examiner for the Royal College of Surgeons Edinburgh.

\section{Why dentistry?}

I've never really known otherwise. When I was three years old my father said 'I think dentistry would suit you'. He was right!

This was in Denmark. My father worked for Ilford [Film] as a representative and he used to visit the radiology department at the dental school. He saw the dentists hard at work in the clinics and completely concentrated on their patients. He liked that. clear that I also enjoyed every day interaction with and exposure to new people and the overall concept of caring for dental wellbeing.

\section{Why prosthodontics?}

Somehow the overall understanding of my undergraduate dental course seemed to come together in prosthodontics. Today we refer to prosthodontically driven treatment and I think I could see even then that the different

\section{'When I was three years old my father said 'I think dentistry would suit you'. He was right!'}

This was around 1963 and, as a girl, my father felt that it was important that 1 aimed for an education that would allow me to stand on my own two feet through life.

As I grew up, this guided me through my choices at school and gave me a focus. The grades for gaining entry to the dental school were high but I made it in and fortunately, I enjoyed both being a dental student and later a dentist. It suits me, and it's worked so well for me as a working mother. The flexibility has been great.

To begin my interest was probably mainly in the craft of dentistry itself. But it soon became treatment disciplines all contributed towards that end result.

I realised in my last term that my particular interest was in removable prosthodontics. I found that I understood partial denture design and the now widely recognised Scandinavian hygienic principles. At the same time I recognised the enormous importance and patient benefit of successful complete dentures. But I also developed a healthy respect for them because they required not only my best efforts but also those of my patients to overcome inherent functional limitations.
I was fortunate enough immediately after my graduation to get a position as a clinical assistant in the prosthetics department at the Royal London Hospital. That is where the concept of care and contribution to patients' quality of life really dawned on me. I was shadowing my colleague, Julia Davis, and when she took me to a geriatric hospital, something went off like a lightbulb - I was so impressed with the care that she was providing for these elderly patients and the significant change her dentures made to their lives.

\section{You qualified in Copenhagen, what brought you to the UK?}

It's simple. I couldn't get a job there at the time of graduation. There weren't enough jobs for newly qualified dentists at that point, so I had to look abroad.

The UK was a logical choice. My mother was a teenager through WWII and a great anglophile. My father worked for Ilford -a big British company - and would very often travel to the UK with his customers so I grew up hearing about Britain and London. The first time I travelled abroad by myself was on a language course to Bournemouth. I was 16, it was the glorious UK summer of 1976 and I just loved England. 


\section{What have been the biggest challenges in your career?}

The first big challenge was that there were no jobs for dentists in Denmark at all when I qualified. I had been so focused on becoming a dentist, so it was quite a shock to realise that I might never get to practise. Denmark has always required a vocational training year after graduation and this had to be completed before I could gain my full authorisation and practise independently.

There was a five- or six-year period in the mid-80s when there were no jobs for dentists in Denmark. I am not quite sure why this happened, but it affected us all. Out of my group of 12 graduates, 11 went abroad.

With my preference for moving to the UK, the next big challenge was to overcome my lack of full authorisation from Denmark. I could only get temporary registration with the GDC and, as this was before the introduction of the UK vocational training schemes, I was limited to training positions in dental schools or dental hospitals. It was very difficult to obtain one of these positions from abroad.

The third challenge was to take over a portfolio of implant patients in the mid-90s when we were all at a relatively early stage on our collective learning curve in implant dentistry. I was suddenly faced with a wide variety of the biological and hardware complication we have a much clearer grasp on today. At the time, however, we were seeing many of these for the first time and it was a daunting task to manage a group of disillusioned patients and their serious complications, many of which were a challenge not just for me but also my more experienced mentors.

I suppose a fourth challenge, and one that we are all faced with, is how to keep up the interest and motivation in our daily work. I have been very pleasantly surprised at the many further opportunities that have come along over the years for stimulating and maintaining interest. Initially, this was predominantly through giving CPD courses and being a vocational trainer. Later my various additional roles have involved me writing articles and text book chapters, editing online learning modules as well as leading projects and organising conferences.

Two particular motivating factors continue to be my interest in removable prosthodontics together with my wish to establish worldwide sound, robust introductory training in implant therapy for safe and predictable treatment of our patients.

\section{Was it daunting coming to work in the UK?}

Absolutely, but in a good way. Upon arriving to work in the UK, dental needs were very different. If you were interested in removable prosthodontics, this was the place to come.

I started out with five years at the then London Hospital Medical College Dental School and I gained plenty of practice of resolving difficult denture situations. The prosthetic department was really good with a large faculty of lecturers and consultants, so there was extensive experience and a huge variety of approaches to draw on in learning how to tackle these difficult situations.

After the first five years, I felt it was time to gain broader experience across dentistry, so I went into general practice. I was very fortunate to find an excellent practice where I stayed for nine years before my continued end result should drive treatment planning and execution, so it naturally ties together all the other disciplines that contribute to the overall treatment process.

Look carefully at what each specialist training programme offers. The prosthodontic spectrum is very wide now. Implant-based solutions are well established, but the traditional conventional options also continue to have their place. It is still essential that a specialist prosthodontist can make good conventional partial and complete dentures. A prosthodontic specialist needs to be able to provide patient-centred rather than technique-based solutions.

\section{Why do you think occlusion is such a source of disparate views in dentistry?}

That's a difficult question to answer! Probably because there are such disparate views on its importance. As dentists we are involved in occlusion every time we touch a tooth surface and it is very difficult to reproduce

\section{'I recognised the enormous importance and patient benefit of successful complete dentures'}

interest in removable prosthodontics moved me on into a multidisciplinary practice where I worked for the next 21 years.

About a year ago, I decided maybe the time had come to go it alone so I did. Now, I rent my space and work under someone else's umbrella but I am essentially independent. It's been a very positive change at this professional stage and it's worked out really well.

\section{What three tips do you have for someone looking to specialise in prosthodontics now?}

Gain a broad working knowledge and experience of mainstream dentistry and minor oral surgery first. It's really important to have a good, broad basis of exposure to the restorative disciplines, practising at the coal face in general practice and getting a lot of experience. It maybe takes two or three years before you get there.

Consider whether to go for the broader specialist restorative training or focus directly on prosthodontics. If I had had the option of the structured training paths that are available now, I would have opted for the full restorative specialisation. The prosthodontic the surface details exactly. Fortunately, our patients' neuroplasticity allows them to adapt to almost anything and so for the most part, we get away with occlusal changes.

There is no evidence-based concept for an optimal occlusion and the natural occlusion schemes that pass through our hands daily show immense variation. So it is a difficult topic to get your head around. Then there is the debate as to the extent the occlusion triggers signs and symptoms and whether we can or should address these. Again, there is little hard-core evidence to prove that it does or that we should.

Nonetheless, it must be logical that we pay the same respect to the occlusal aspects as to any other aspect of the teeth and dentitions we restore, and we should therefore seek to preserve their natural characteristics. Where teeth are missing, and restoration of occlusal function is needed, it is equally logical that we must be able to reinstate this in a predictable, comfortable and durable manner. We may be limited to best available guidelines, but if we are involved in creating new occlusal schemes, fixed or removable, we need to know how to implement these. We also need to be able 
to manage any signs and/or symptoms that might arise as a result of that process.

\section{What other aspects are there to your work?}

I lecture regularly and I enjoy this educational aspect of my working life. I am a lecturer at the Division of Gerodontology and Removable Prosthodontics, University of Geneva and examiner for the Royal College of Surgeons Edinburgh.

I am also heavily involved in organising education programmes for the International Team for Implantology [ITI] and I have been both education delegate for the UK and Ireland Section and a member of the ITI Education Committee for many years. I am also a founder member of the ITI Online Academy as well as its immediate past editor-in-chief.

Now I head up global implementation of a universal, standardised ITI implant curriculum for newcomers to implant dentistry. This implant curriculum is based on a very successful year-long ITI foundation programme that was put together by regarded as a team discipline than a specialism. But I am also aware that an argument for making implant dentistry a specialism is to be able to regulate it better.

\section{'Out of my group of 12 graduates, 11 went abroad'}

the UK \& Ireland Section during my time as education delegate, and which has been running for ten years.

\section{Should implants be a specialism?}

Another difficult question! I believe that both the UK and international consensus opinion is that it's not a specialism. Implant dentistry crosses different specialist disciplines including prosthodontics, oral surgery and periodontics and as such, it is perhaps better
If you had to live and work anywhere other than the UK - where would that be?

I have been very happy and continue to be happy here. I have been fortunate that I now travel increasingly through my various dental roles and it gives me an opportunity to visit other countries and meet their dental professionals. But Brexit allowing, this is my home and this is where I would like to stay and practice!

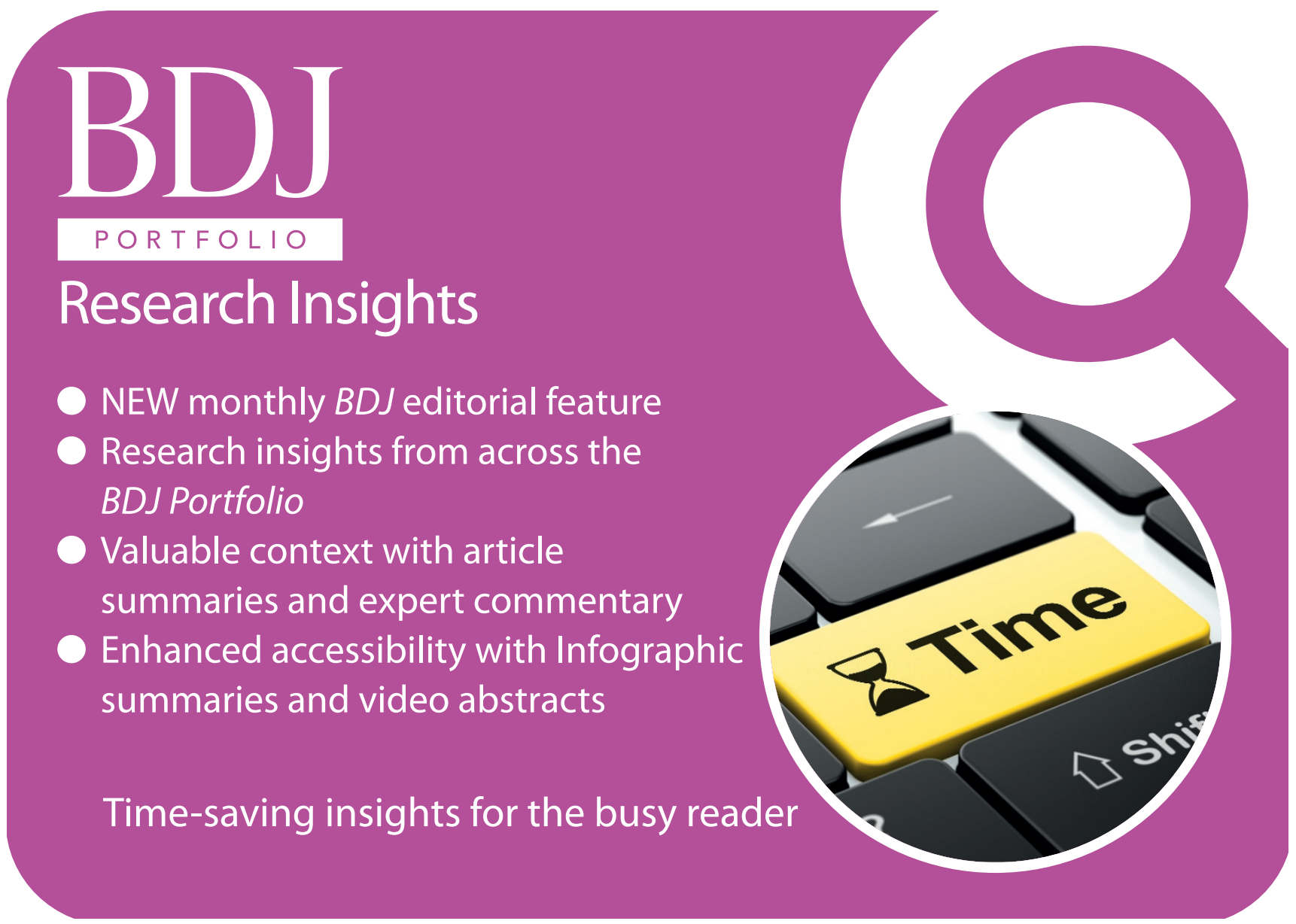

